\title{
1. Introduction to The Politics of Regional Cooperation and the Impact on the European Union
}

Over the last decade the European Union has gone through some of the worst crises of its existence: the Euro-zone crisis, the Ukraine crisis, the Brexit crisis and the so-called migration crisis (see, e.g. Börzel and Risse 2019). The crises have created new cleavages within the EU, with primarily the Euro-zone crisis contributing to a North-South division and the migration crisis to an EastWest cleavage. At the same time, enlargements and the continued deepening of the integration process have rendered a situation where member states' interests in the integration process have become more diversified (Schimmelfennig and Winzen 2017). In this more heterogeneous EU, organized subregions and other forms of subgroups of member states within the EU with various forms of pre-meetings prior to councils/European Councils are a frequent component of EU life. Yet, there has been only limited attention paid to subregions by the scholarly community. Against this background the book elaborates on the contemporary role of subregions within Europe, and the European integration process.

The book asks the question of what subregions in a European context are and what role(s) they fulfil in relation to the European integration process. There are different definitions in the literature of what constitutes a region. A common approach is to assume that there is no fixed definition since regions are social constructs, but to assume that an international region should include more than two countries (Börzel and Risse 2018). Since the term 'region' often is referring to a continental region such as Europe, other terms have been introduced in the literature to refer to regions located between the bigger region and the state level. Thomas Christiansen (1997) referred to such regions as meso-regions, in more recent EU literature the term macro-region (see, e.g. Gänzle and Kern 2016) has become popular. The latter concept has in the literature become near-synonymous with the EU's usage of the term with reference to the Union's macro-regional strategies (Dangerfield 2016).

In the book, the concept subregion is used since there is a large literature utilizing this concept (see, e.g. Cottey 1999; Dangerfield 2001; Dwan 2000; Fawn 2013), being aware, however, of the existing overlaps between this 
concept and the rival ones. Independent of which label we give to these regions, they have in common that they refer to international regions, consisting of at least three different countries and that they are at the same time a part of a bigger region. The book shows that one of the specific characteristics of subregions is that the area of the subregion is not sufficient for providing solutions to economic, security and other forms of interdependence among its members. The states therefore need the larger integration in the bigger region to provide functional governance and to effectively deal with economic interdependence (the European Union) and with security (NATO). Therefore, the subregions in most cases cannot provide a substitute for the bigger region(s). This is also why some existing categorizations of subregions in Europe are based on how they relate to the European Union and the European integration process (see, e.g. Dangerfield 2008). Despite this, European subregions have developed surprisingly persistent forms of cooperation and integration. The Visegrad Group was not expected to survive fulfilling its main mission, in other words its member states' inclusion into the European Union and the North Atlantic Treaty Organization, and the Nordic cooperation was expected to lose its importance after the end of the Cold War as a consequence of the European unification process.

Subregional forms of cooperation in Europe, however, have maintained their relevance even if subregionalism largely takes place in the shadow of the broader European integration process. The book suggests that subregions fulfil two specific functions in relation to the European integration process; they (a) compensate for the EU's horizontal and vertical differentiation (Leuffen et al. 2012), in other words they facilitate cooperation and integration in areas where the European process is less developed and/or compensate for differences in how countries in a subregion are connected to the European integration process, and (b) they enhance the voice of the countries of a subregion within the European integration process.

The subregions can also lead the way and serve to develop integration that later generates similar developments at the European level. Subregional integration in both the Benelux and the Nordic countries preceded the European integration process. The design of the European Economic Community was inspired by the Benelux Union, which was initiated through the customs' union signed already in 1944 (Dinan 2014). Moreover, the subregional cooperation in the Nordic region experienced an early boom in the 1950 s with the establishment of the Nordic Council in 1952 and, for instance, the removal of passport controls between the countries by 1958, and the subregions can very well serve to inspire the European integration process also today. The Nordic Council of Ministers, for instance, has the declared ambition of becoming the 'most sustainable and integrated region in the world by 2030' (Nordic Council of Ministers 2019). 
Moreover, the distinction between what is a 'subregion' and what is a 'region' changes over time. When the European integration process that today has evolved into the European Union started with the Treaty of Paris in 1951, this was in reality West European regionalism. The six founding West-European member states, however, considered the organization pan-European which is visible in the Treaties of Rome signed in 1957. According to Art. 237 of the Treaty Establishing the European Economic Community, all European states can apply for membership. In the context of the Cold War the European Community's commitment to consider membership applications from any European country was more of a rhetorical commitment than a substantial issue. However, as Frank Schimmelfennig (2001) demonstrated, the ideological commitment to Europe was important for how the EU dealt with the Eastern enlargement and the accession processes that started in the 1990s. Only with the first wave of the Eastern enlargement in 2004 can we speak of the EU as a pan-European organization. It is important to remember that when the Maastricht Treaty was signed in 1992, there were only 12 European leaders signing the treaty.

In a longer historic timeframe the distinction between what is a subregion and what is a nation state might also be challenged. Some historians have suggested that subregions were more important back in medieval and early modern periods compared to contemporary Europe, while in contemporary Europe subregions have lost much of their relevance due to the development of the territorial nation states and the European unification project (Mishkova and Trencsényi 2017, p. 213). The Nordic subregion is an example of a region where there was a strong movement in the 19th century for the unification of the subregion - Scandinavia. Scandinavianism as a movement was in particular strong among intellectuals and in university cities. If history would have been slightly different, we could today have viewed Scandinavianism as one of the national unification movements of the 19th century (Hemstad 2008). However, despite the fact that the Swedish historian Gunnar Wetterberg in 2010 caused debate throughout the Nordic subregion with a book, commissioned by the Nordic Council and the Nordic Council of Ministers, where he proposed the development of a Nordic United Federation (Wetterberg 2010), any proposal for a Nordic state has to be considered utopian and highly unlikely to materialize at least within the foreseeable future, despite a strong poplar support in the region for Nordic cooperation (see, e.g. Nordic Council and Nordic Council of Ministers 2017a).

The book proposes a theoretical framework based on postfunctionalism for the study of subregional cooperation and integration. The framework suggests that regionalism largely develops because of functional pressures, in other words, as a response to various forms of interdependence between countries of a (sub)region. Yet, functional benefits are not sufficient on their own for 
the development of cooperation and integration within a territory. Identity is also viewed as a crucial variable that can facilitate such a process but also become an obstacle for integration (Hooghe and Marks 2009; Börzel and Risse 2019; Braun 2020). Subregions do not automatically have an advantage when it comes to the possibility of generating identification and engagement for their narrative among the broader population. The subregions' sustainability over time, however, suggests that the topic of subregional identity should be approached and examined. Moreover, subregional identity is a crucial factor for how the integration and cooperation in the subregions shall be understood, and what kind of developments we can expect of these cooperation forms in the future. The topic of subregionalism is in particular of importance at a time when there are several challenges to the future of the European integration process and the future of Europe is open to debate.

\section{WHAT IS A SUBREGION?}

Today, the main examples of the subregions within or partly within the area of the European Union would include the Benelux group consisting of Belgium, the Netherlands and Luxembourg, the Baltic states (Estonia, Latvia and Lithuania), the Nordic Council (Denmark, Finland, Iceland, Norway and Sweden), and the Visegrad Group (Czech Republic, Hungary, Poland and Slovakia). Other formations are also present but over time less coherent in presenting the countries as a region, that is, the Weimar Triangle (Germany, Poland and France), the New Hanseatic League (the Nordic EU members, the Baltic States, the Netherlands and Ireland) and others. Within the Council diplomacy of the EU all these formations have similarities and resemble what in the literature has been labelled 'territorially constituted coalitions'. They strive for enhancing their bargaining capacity for instance by sharing information, pooling expertise and rhetorical action (Rüse 2014). They, however, are very different when it comes to the degree the cooperation has been formalized and the duration of the cooperation. Moreover, groups like the Visegrad Group and the Nordic Council aim at more than merely coordinating the positions of the countries within the EU; the Visegrad Group has for instance also developed defence cooperation, albeit with various levels of success (Kolmašová 2019), and the Nordic Council has institutionalized cooperation that predates the European Economic Community.

Subregional cooperation refers to 'a process of regularized, significant political and economic interaction among a group of neighbouring states' (Dwan 2000 , p. 81). European subregions vary greatly to the degree that they engage in formalized cooperation. Whereas, primarily, the Benelux Union is based on a treaty and the group has a fixed headquarters, the Visegrad Group (V4) is based on formal agreements between the participating countries but lacks 
a specific secretariat. The V4 however, has gradually enlarged its cooperation with increasingly substantial programmes of the group's annually rotating presidencies (Fawn 2013), and since 2000 the group has established the Visegrad Fund with a permanent seat in Bratislava. The cooperation between the Nordic countries is formalized in the Nordic Council and the Nordic Council of Ministers, but since not all the Nordic countries are EU members the Nordics also meet in a less formalized cooperation which often takes the form of the Nordic Baltic 6 (NB6), which is an offspring of the Nordic Baltic Cooperation (NB8) which includes the countries of both the Nordic and the Baltic Councils. The NB6 has in turn developed into an institutionalized but highly informal consultation group which does not operate based on any formalized agreement and in the period of Brexit negotiations these countries also met in an extended format which then also included the Netherlands and Ireland; a cooperation form which now goes under the label the New Hanseatic League (Korteweg 2018).

The previous literature has viewed contemporary developments in the subregional cooperation as evolving in response to the European integration process. The probably most well-quoted typology of subregional cooperation in Europe comes from Martin Dangerfield (2008) and is illustrative in this regard. Dangerfield speaks of four types of such cooperation which all refer to how the subregions relate to the European Union: (1) pioneers; (2) complement/pre-accession instrument; (3) substitute; and (4) involuntary alternative/substitute. The pioneers are the forms of subregional cooperation that predate the European integration process, that is, the Benelux cooperation and the Nordic cooperation and are therefore viewed as paving the way for the European integration process. The complement/pre-accession instrument refers to cooperation entities formed with the intention of accession to the larger project of regional integration, for example, the Central European Free Trade Agreement. The substitute is viewed as attempts of forming an alternative to the dominant form of regional integration in the area, for instance the European Free Trade Association. The involuntary alternative/substitute category is hypothetical but thoughts of being excluded from the European Union and instead forced to integrate more with each other was a perception that influenced the debate on the Visegrad Group in the 1990s.

The cooperation and integration in the subregions tend to be supplementary to the integration process in the European Union as such. Moreover, the cooperation in the subregions is most often cooperation that includes only limited integration, in other words the cooperation in the subregion does not tend to generate the pooling of sovereignty that characterizes the European integration process. Subregions with more or less institutionalized forms of cooperation also attempt to influence the European Union. These groups are referred to by different names in the literature such as alignments, partnerships, blocs, coa- 
litions, groupings or territorially constituted coalitions (Rüse 2014). Recently, in particular the V4 has managed to coordinate some of the countries' work in Council negotiations, for instance relating to migration and climate policies (Braun 2019), and in the context of the UK leaving the EU, senior diplomats in the Nordic region called for increased Nordic Baltic cooperation in the Council work to compensate for the loss of the UK that often was a close partner to the countries in Council negotiations (Fjellner et al. 2018).

\section{WHY STUDY SUBREGIONALISM?}

The European Union has, during the last decade, gone through several crises: the Euro-zone crisis, Brexit, the migration crisis and the Ukraine conflict, including the Russian annexation of Crimea, that constituted a crisis for the EU's neighbourhood policy. The crises have made it increasingly relevant to study subregionalism in Europe because (a) they show that the European integration process is less exceptional than often argued, (b) they suggest that the integration process is getting more differentiated, (c) in a more complex EU without the UK there is an increased need for coalition building among smaller states, and (d) regarding some of the crises, but not all, the responses to the crises have stressed similarities between countries of a specific subregion.

In 2008 a global credit crunch began in the USA and quickly spread across the globe and turned into a crisis for the EU's common currency, the euro. The situation escalated into a crisis of the common currency due to the high levels of public and/or private debt in some member states. The Euro-zone crisis led to increased discussion within the EU on the topic of differentiated integration. Because of the crisis it was assumed that the Euro-zone had to integrate further, whereas in several non-Euro-zone EU member states the willingness to introduce the common currency decreased. Therefore, it was predicted that the distinction between EU members in the Euro-zone and those outside of this would become both more substantial and long-lasting (Beneš and Braun 2014).

In 2016 a referendum in the UK resulted in a decision that the country would withdraw from the EU. The result led to long negotiations on the future relations between the EU and the UK that at the time of writing (June 2020) have still not been completed. A key point in the debates has been how closely affiliated the UK after withdrawal will be to the broader process of European integration and some scholars have introduced the concept of differentiated disintegration that indicates that the distinction between membership or non-membership of integration is a gradual scale where also disintegration can take place to various degrees (Schimmelfennig 2018). Furthermore, in the wake of the UK's decision to exit the EU the Commission initiated a debate on the future of Europe. The Commission's White Paper on the Future of Europe included different scenarios for the future of the Union whereof one was 
labelled 'Those Who Want More Do More' and was clearly based on the idea of a more differentiated integration process.

In Ukraine in 2013 the failure of the then President Viktor Yanukovych to sign the Association Agreement with the European Union sparked protests and led to the president's ousting in February 2014 (see, e.g. Haukkala 2015). The development has been referred to as the Ukraine crisis and was followed among others by the Russian annexation of Crimea in March 2014. For the European Union, the developments in Ukraine can be considered a crisis of its neighbourhood policy in general and more specifically of its approach towards the countries of the Eastern partnership. The European Neighbourhood Policy (ENP) is based on the idea of being just like enlargement but without the perspective of EU membership. The ENP aims at the extension of EU values and norms to the neighbouring countries by using conditionality based on a combination of carrots and sticks (Raik 2019). What happened in Ukraine showed the limitations of the EU's approach. There has been criticism of the ENP since its beginning in 2004 primarily based on the assumption that the conditionality only works if the reward for compliance is substantial enough, which was the case with EU accession, but critics doubted that the process would work when the possible rewards for the target countries did not include EU membership. The European Neighbourhood Policy, however, is based on the idea of differentiated integration since the idea is to create a ring of friends that are integrated to various degrees with EU norms and formal legislation (Schimmelfennig 2016) and the consequence of the Ukraine crisis is likely to escalate the differentiation between different countries further and blur the line between membership (which at the time is missing from the agenda) and non-membership.

The issue of migration has been on the EU agenda for some time. The EU has tried to reform its common asylum policy on a few occasions but without managing to substantially change the system based on different versions of the Dublin regulation (Monar 2017). The unprecedented high inflow of asylum seekers starting in the year 2015 caused the system to collapse, in the sense that some of the external border countries failed to register migrants who arrived, and who could then continue travelling to other final countries of destination in the EU's Northern and Western parts (see, e.g. Niemann and Zaun 2018). The situation made EU member states reintroduce border controls and the Schengen area was in effect largely deactivated. The discussions of how to solve the issue became fierce and created tensions between Eastern and Western member states, even if the debate in reality was more complex (Zaun 2018). The Visegrad Group became a visible proponent for a restrictive line on migration, demanding enhanced border protection and rejecting schemes for the redistribution of asylum seekers within the EU. It was not the first time the 
group managed to coordinate its positions within EU negotiations, but was the most visible (Braun 2020).

The four different crises of the integration project mentioned here have several implications for the issue of subregional cooperation and integration in Europe. The first implication is about the general consequence of the crises for our understanding of European integration. In the aftermath of the EU's multiple crises it has become commonplace to discuss integration theories from the perspective of how well they can explain integration in the reverse and disintegration (see, e.g. Börzel and Risse 2019), and it has been suggested that the EU is more similar to other projects of regional integration than previously assumed. That is, in particular the British withdrawal from the EU has led to calls for increased studies of comparative regionalism to grasp the commonalities of regional integration in different geographical locations. In this context we should also pay attention to the subregions within Europe. The suggestion is not that it is likely that the subregions would replace the European integration process. Even in the cases where the initial subregional project included ambitions to be a substitute to West European integration, as in the case with Nordic integration, this aspiration was quickly abandoned, and few would argue that any of the subregional groups could provide the same economic benefits as the EU's single market. Yet, the crises of the European integration process show that we should not take its exceptionalism for granted and a better understanding of subregions can also shed new light on the European integration process.

Second, the crises of the integration process are all linked to the issue of differentiated integration. The fact that the European integration process is differentiated both in a horizontal way (all member states are not integrated to the same degree) and a vertical way (all policy fields are not integrated to the same degree) is in itself nothing new. Examples of differentiation can be found long back in the history of European integration (see, e.g. Tekin 2012; Stubb 1996; Leuffen et al. 2012). However, in the current situation it is acknowledged that the differentiation is more substantial, that the horizontal differentiation includes both members and non-members, and that it is not the question of multi-speed integration where all the countries will eventually catch up and be integrated to the same degree sometime in the future. In a Europe of differentiated integration it is plausible that subregional groups could play a role to allow the countries of one subregion to develop further integration in one area to compensate for shortcomings of the general integration process and/ or to satisfy specific subregional demands. The subregions to some degree either already fulfil such tasks or are involved in work to develop their cooperation further to do so. The Nordic subregional cooperation among others addresses the issue of horizontal differentiation of the European integration process in a situation where not all its members are fully fledged members of 
the European Union (see Chapter 4), and both the Nordics and the Visegrad Groups aim at developing cooperation in fields where the EU cooperation is less developed (vertical differentiation), such as in the field of defence and security policy. The expectation is not that the subgroups per definition in any way would desire a more differentiated Europe where they could play stronger roles. The Visegrad Group, for instance, has in the debate on the future of Europe strongly rejected the vision of a future more differentiated EU, stressing the need for a coherent Union (see Chapter 5). This, however, does not rule out that the V4 in its activities responds to a more differentiated integration process.

Third, in a European Union without the United Kingdom the dynamics of Council negotiations change. It is the smaller countries that have the stronger needs of forming various kinds of coalitions and partnership to enhance the bargaining power within the Council. The coalitions formed do most often not lead to formal voting blocs generating blocking minorities. Their usefulness is rather for the countries to pool expertise and share information necessary for generating qualified positions, and to assist each other in articulating the issue. Smaller states have fewer resources and are for that reason more likely to engage in this form of cooperation (Panke 2010; Rüse 2014). In the EU without the UK the possibility of small states to team up with one of the big states becomes smaller and the importance of Germany and France for the decision making is likely to increase (see, e.g. Hix et al. 2016).

Fourth, the crises are illustrative of how the subregions often engage with similar problems, but it should be remembered that geographic approximation does not always lead to similar interests. Research about voting behaviour in the Council has shown that there is some correlation between geographic location and voting behaviour (Mattila 2009). More often it is perceptions about the group in the same geographic area that make both external and internal observers assume groups of countries in the same area have similar interests. The Nordic countries in relation to the Euro-zone crisis is a good example of this. For some time, there were plenty of articles in the news coverage about the Nordic social and economic model as an alternative to the neoliberal economic order that was challenged by the financial crisis (see, e.g. The Economist 2013). Independent of if there actually exists anything that could be labelled the Nordic model or not, the perception of the existence of such a model is important for why there is such a strong support for Nordic cooperation within the subregion itself. The Nordic countries are in many ways extremely different, two of the five countries are not members of the EU, two of the three countries that are members of the EU are on the other hand not members of NATO. Among the Nordic countries that are members of the EU the actual policy interests in the integration process differ widely - compare for instance Danish and Swedish approaches to the EU's Common Agricultural 
Policy (see, e.g. Nedergaard and Jensen 2015). The Visegrad countries on the other hand were happy to stress during the so-called migration crisis that they were the main proponents of a restrictive migration policy. This was then an issue that united the group and made the group appear as more coherent than it actually is, even if the V4 are all NATO and EU members they differ greatly for instance in their approach towards Russia (see, e.g. Dangerfield 2012). Yet, in a period of crisis, perceived similarities between neighbouring countries is a factor that can facilitate further cooperation in the subregional formats.

\section{UNDERSTANDING REGIONALISM - A PERSPECTIVE BASED ON FUNCTIONALISM AND IDENTITY}

During the last few years one of the most commonly referred to concepts in the study of European integration is that of postfunctionalism (Hooghe et al. 2018; Börzel and Risse 2019). The concept initially was primarily associated with the idea that at a certain point in time the process of European integration gets politicized and when that happens the elite-led integration process would be challenged by a popular constraining dissensus that replaces the previous permissive consensus on European integration (Hooghe and Marks 2009). The assumption is that when politicization of the integration process escalates, broader masses pay more attention to integration and this development also means that identity becomes more important, and even decisive for the integration process. Hooghe and Marks speak in terms of exclusive and inclusive national identities. If people in a territorial state largely consider their national identity exclusive it is more difficult to convince them about the advantages of governance at the supranational level, whereas the opposite would be the case regarding inclusive national identity. The theory, however, says relatively little about how identity is constructed and how it develops, except for suggesting the relevance of political entrepreneurs when it comes to articulating the relevance of identity regarding a specific issue. For this reason, it has been suggested that the theory would benefit from constructivist insights regarding identity (Börzel and Risse 2018).

The theory explains the process of integration with the starting point in the two concepts of multi-level governance and functionalism. According to Hooghe and Marks $(2009 ; 2019)$ a functional rationale leads the governing elite to select governance at the level where it is appropriate for efficiency reasons. Even if rational national decision makers do care about the country's sovereignty, this is not the only issue of importance to them and integration takes place because they see other concrete benefits with the integration process; these can be economic but also security related, for example. The theory does not assume that European integration is a Pareto optimal solution being profitable for everyone involved, only that nation decision makers at 
the time of the decision see benefits coming from the outcome, even if this can in the end for instance be beneficial only to one important constituency (Hooghe and Marks 2009). For this reason, the theory suggests that integration is a response to functional pressures, in other words, that interest groups would articulate the benefits of integration within specific sectors (Börzel and Risse 2019). In that sense the starting point for answering the question why integration happens is not all that different compared to neo-functionalism, liberal intergovernmentalism or any other integration theory rooted in a liberal tradition of international relations. These theories, however, suggest the primacy of economic interdependence, and that integration is primarily driven by economic reasons where geopolitical and ideational reasons would be only of secondary importance (Moravcsik 1998). Postfunctionalism does not necessarily privilege economic interests - the functional gains could potentially be just as well about security, or for a power elite to tighten their grip of power in the context of regionalism in non-democratic settings (Libman and Obydenkova 2018) and then there is the aspect of identity often ignored by many rationalist liberal integration approaches.

Even if the theory of postfunctionalism expects functional reasons to be the actual drivers for integration, viewed in isolation functional pressures do not necessarily lead to integration. The theory assumes that citizens care about who governs over them. Therefore, if citizens cannot associate with the territory of governance, they are less likely to accept it and political entrepreneurs can then utilize opposition to the integration project and gain popularity. Therefore, in the European context where elites have been able to develop a complex form of integration with a well-developed institutional framework, at a certain point you can expect a 'postfunctionalist moment' (Schimmelfennig 2014) where the popular constraining dissensus puts negative pressure 'on the level and scope of integration' (Hooghe and Marks 2009). In other words, at a certain point the expectation would be that the integration process cannot develop further without the population identifying with the unit of regionalism. It is difficult to predict the consequences of a postfunctionalist moment regarding the future of the EU. Some authors have used the theory as an explanatory framework for Brexit (Schimmelfennig 2018). Conclusions from the Euro-zone crisis, on the other hand, suggest that governing elites might be able to prevent a constraining dissensus from having any impact on the outcomes of integration. Several of the responses to the Euro-zone crisis have implied more integration rather than the opposite (see, e.g. Schimmelfennig 2014; Vilpišauskas 2013).

Postfunctionalism as a theory provides a suitable framework for an understanding of an increasingly differentiated integration process. Schimmelfennig et al. (2015) have suggested that interdependence is the explanation of why we see vertical integration in some policy fields but not in others. When an issue/ policy area is politicized in several member states we are likely to see a popular 
constraining dissensus and thus a lack of integration in the area, however, when the politicization only takes place in a few states, the outcome is likely to be horizontal differentiation of the integration process.

Postfunctionalism, however, can also serve as a framework to identify where integration is likely to happen and where regions are likely to be built through the activities of political entrepreneurs, interests groups and political decision makers (Neumann 2003). The framework suggests that integration is likely to happen in regions where: (a) functional demands for regionalism exist based on a broader concept of interdependence (not exclusively economic) and (b) the elite's efforts at regional identity-building resonate with the public in the region (Börzel and Risse 2019). These two components are relevant for the subregions as well. Yet, in most cases the subregional projects have not developed much of actual integration if we by integration mean the development of supranational elements with shared legislation and supranational legislation. The amount of integration developed as a consequence of subregionalism is limited, since the subregions are considered too small to solve issues related to mutual interdependence. The Nordic cooperation might have the ambition that the region will become the most integrated region in the world by 2030 (Nordic Council of Ministers 2019). Yet, the cooperation mostly takes the form of intergovernmental cooperation with an emphasis on consultation and softer policy fields, such as cultural policy, despite some major steps of integration in the 1950s. The second subregion covered in this book, the Visegrad Group, has primarily integrated in response to the broader process of European integration. Yet, in the context of a more differentiated integration process subregions could be assumed to play a more substantial role in the future, even if it is highly unlikely that they could develop into real substitutes for the European integration process.

When it comes to the second condition related to identity, a sense of a shared belonging is relevant to discuss in relation to subregions since this is not only relevant for how far the subregions could serve as starting bricks for the building of more integration and how far they could generate more integration to compensate for the differentiation of the European integration process, but also regarding their possibility to function as coalitions within the European integration process. Therefore, the book sets out to examine how the subregions relate to the issue of identity. Geographical appropriation does not necessarily mean that the populations in the countries would identify themselves with each other or that there would exist an identity narrative of the group. In one of the regions under examination in the book, that is, the Nordic region, there is a long tradition of viewing the countries as parts of one region with specific cultural affiliation, whereas in the other example, the Visegrad Group, the concept does not represent an area which traditionally has been 
considered a region with borders similar to that of the countries participating in the group of today.

The book also addresses identity as an outcome of cooperation. In other words, the book examines how the cooperation in two selected European subregions can contribute to the development of a common (sub)regional identity. The identity factor is crucial since this can both serve as a facilitator for further cooperation and as a hindrance to cooperation and integration. Previous research has in this regard primarily targeted the possibility of the development of a common identity at the EU level, which could facilitate further integration, and how the presence of exclusive national identities in the member states hamper further integration. Identity has, in the research on regionalism, been treated both as the independent and the dependent variable. In some research the question has been about how a common identity facilitates integration, whereas other research has treated identity as an outcome of integration (Checkel 2016). The research presented in this book highlights how subregional cooperation can both be the consequence of, and contribute to, the development of a common identity in a subregion.

The postfuctionalist literature provides a satisfying account as for when identity matters in the European integration process. The theory, however, deals with identity in a simplified manner based on assumptions referring to exclusive and inclusive national identities. For this reason, for instance, Tanja Börzel and Thomas Risse (2018) have called for utilizing 'insights from social constructivism with regard to identity' (p. 102). For this reason, the book draws on two sets of constructivist literature on identity within which identity is linked to narratives; in other words, stories about the group in relation to others (Eder 2009).

\section{SUBREGIONS AND IDENTITY}

With the linguistic turn in international relations in the early 1990s (Neumann 2002) identity became a key topic of examination through language in the study of European integration. This book works in this tradition and it applies an understanding of identity as being linked to how the collective 'we' is articulated. It therefore suggests that official rhetoric of the group is crucial for developing a narrative that legitimises the existence of the political region. The research is in this sense inspired by approaches utilized in relation to the European integration process (see, e.g. Diez 2001; Jachtenfuchs et al. 1998; Larsen 1999; Hansen 2006; Wæver 2009; Biegoń 2013).

Since the 1990s a large literature has developed which argues from a critical constructivist or post-structuralist perspective that national identity in some cases hampers the attempts of political and economic elites to justify European integration (see, e.g. Diez 2001). Another set of works has delved into how 
an emergent European identity can be analysed from a discourse analytical perspective. In this literature, often inspired by Michel Foucault, identity is understood as a discursive construction which, albeit changing, is difficult for elites to control and change in an aware way, but where legitimization strategies of the EU take place within a discursive space, which in some studies have been understood as narratives (see, e.g. Biegoń 2013).

The suggestion here is that in a similar vein as narratives serving for the legitimization of the EU can be identified through analysis of the legitimizing discourse of various actors involved in the European integration process, the same can be carried out at the subregional level. The suggestion is that, for instance, the meaning of Central European identity has changed through a shift in the dominating narrative in the region, from back to Europe and in the aftermath of the migration crisis to a rejection of a liberal humanitarianism associated with the EU. The suggestion here is not that the subregional forms of cooperation should be compared to the EU, nor that the narratives of the subregions fulfils the same legitimization task. The suggestion is merely that the narrative in the long-term perspective contributes to the development of a sense of shared identity within the participating countries which has consequences both for the subregional cooperation and for the broader process of European integration.

The specific approach utilized in the book is most directly inspired by Ian Manners and Philomena Murray (2016). In line with this approach, in the empirical chapters attempts are made to deconstruct the selected narratives in the subregions according to the following components: (1) structure, which refers to the chronology and plot of the narrative, (2) identity, referring to how the narrative provides a 'recognizable story of what' the group's identity consists of, (3) engagement, meaning how the population engage with the narrative, (4) change, referring to how the narrative provides a story of change compared to prior/other narratives of the group and (5) (in)security, referring to how the narrative generates feelings of ontological security.

\section{CASE SELECTION}

There are several ways how we could conceive identity as being under construction in the European subregions. Most of the literature on regions and identity has targeted the European Union (Checkel 2016). Therefore, it is natural for this research project on subregions to take the literature and theories written and developed on European integration as its starting point. However, it is necessary to be aware of several differences between the European integration process and the cooperation and integration that take place within the subregions. First, most of the work carried out by the regional groupings takes rather the form of soft cooperation, in others words it can be in the form 
of policy coordination, consultations, joint projects and so on but it involves only very limited instances of integration if we, by this, refer to supranational aspects of cooperation such as binding shared legislation.

Due to the different forms of cooperation in the subregions compared to the European integration project, the legitimacy claim by subregions is of a different nature, but it is not irrelevant for them and both work actively with the promotion of social integration and with the promotion of shared values among their publics. The question, however, is, given that the subregions include a fewer number of states constituting a smaller geographical territory, do they then have an advantage when it comes to producing a narrative of their common identity? It has been suggested in the previous literature on subregions that some constitute a more 'natural' region than others (Dangerfield 2016). This comment is not to be understood in an essentialist sense. Obviously, a feeling of communal identity within a region as well as within a nation state is something that evolves, changes and is constructed over time. However, a region can over time be more or less of an 'imagined community' (Anderson 1983). As pointed out by Anderson, all communities bigger than small villages are imagined, and the question is thus whether a community exists from the perspective of the population who inhabit a certain territory or not. In the Nordic subregion included in this study there is over time a strong identification with the region, whereas in the Visegrad region this has not been the case. The question this book is investigating is then how far we find indications of identities being under construction within these subregions, and what are the differences in the structure of the narratives in the two different subregions.

The selection of the two subregions, the Nordic region and the Visegrad region, is justified by the fact that they both constitute examples of developed forms of subregional cooperation in Europe. They have in common that they are relevant political subjects in contemporary Europe. However, they are different in many aspects regarding their history of cooperation and how far the cooperation has been formalized. The idea of the book is not to provide a straightforward comparison of the two selected cases of subregionalism. The research design is based on the idea of providing a detailed examination of two different subregions, and more specifically to look into how the cooperation and integration in the subregions facilitates shared identities. If we, despite this, were to apply the language of comparative studies, the selection of the cases would resemble more Mill's method of agreement than the method of difference (see, e.g. Halperin and Heath 2017, p. 218), in other words, the two selected subregions have very different backgrounds and history, and general conditions for possible identity formation but despite this they have both developed comparatively advanced forms of subregionalism. The Nordic cooperation has a long history and there have been ideas about the area as 
constituting one region, or even a nation, at least since the Scandinavianist movement of the 19th century. The Nordic cooperation has therefore often been discussed and viewed as identity-based (see, e.g. Forsberg 2013). The Visegrad countries, on the other hand, have rarely been considered as constituting one specific, limited region prior to the establishment of the Visegrad Group in the early 1990s. The Visegrad countries have even been argued to lack a distinctive Visegrad identity. It was claimed that if there is a regional identity for them, this identity is rather Central European than specific to the four countries in the subregion (see, e.g. Kazharski 2018).

The Nordic cooperation has, in the previous literature, been categorized as a pioneer group, given that the cooperation in several fields developed earlier in the subregion than at the European level. Later it has also served as a substitute, since it bridges EU members and non-EU members, referring, for instance, to the Nordic Passport Union in relation to the Schengen area - which remains crucial not the least for the Faroe Islands that are not a part of the Schengen area. The Nordic cooperation includes both more institutionalized cooperation, which includes all the Nordic countries in the Nordic Council and the Nordic Council of Ministers, and less formalized cooperation within the Council. The Visegrad Group, on the other hand, was initially categorized in the literature as a pre-accession instrument. The cooperation, however, has maintained its relevance and reinvented some of its missions after EU accession. The V4 cooperation is less institutionalized - it, for instance, lacks a permanent secretariat and its only permanent institution is the Visegrad Foundation. The V4's collaboration within the EU has evolved over the last 14 years since the countries became EU members and the cooperation is, for instance, based on well-developed and extensive yearly presidency programmes.

Both subregions have in common that they remain relevant political entities in Europe despite predictions about the opposite. The Visegrad Group was largely viewed as being a pre-accession instrument that would lose its relevance once the member countries had reached the goal of entering the European Union and NATO. In addition, the Visegrad Group faced several challenges in the 1990s linked to the illiberal tendencies in Slovakia, and also due to internal criticism of the cooperation from prominent politicians within the region. There were concerns that the V4 could develop into an involuntary substitute to the EU. This was one reason for criticism against the Visegrad cooperation among some politicians in the region, such as notably the Czech Prime Minister in the mid-1990s, Václav Klaus (1994). Yet, despite this the activities of the Visegrad Group have expanded since accession and over the last few years the popular awareness of the group has increased significantly within the region itself (see, e.g. Ślufińska and Nitzske 2017). Also, in relation to the Nordic subregion, observers expected that the European integration process would make subregionalism redundant after the end of the Cold War. 
The Nordic cooperation, however, has changed remarkably little since the end of the Cold War despite the radical changes in its surrounding world (Olesen and Strang 2016). This could partly be attributed to the fact that two of the five Nordic countries, Norway and Iceland, have remained outside of the European Union. Yet, the distinction between being inside and outside of the EU should not be exaggerated since both Norway and Iceland are parts of both the single market (through the European Economic Area) and the Schengen area, meaning that despite their non-membership of the EU they are very much part of the European integration process (see, e.g. Eriksen and Fossum 2015).

\section{THE STRUCTURE OF THE BOOK}

The next chapter of the book (Chapter 2) is devoted to a detailed discussion of the concept of subregions and of how subregionalism relates to the broader process of European integration. The chapter elaborates on the theoretical framework of the book based on postfunctionalism. The theoretical proposal is that the integration and cooperation in the subregions are linked to (a) how well the subregions manage to deal with economic and other forms of interdependence, (b) how the subregions manage to provide a legitimating narrative and (c) how the countries of the subregions are connected to the European integration process and how well this manages to satisfy the countries' functional needs for regional cooperation. Moreover, the chapter introduces the subregions under scrutiny within this book and examines the functional drivers for cooperation and integration in the two cases. The argument is that the two subregions lack economic and military strength for them to deal with many of the challenges that call for regional solutions but that they still have an important role to play in relation to the European project. The chapter stresses that in both subregions under examination representatives of the regions over the last two decades have emphasized the potential of the subregions as platforms for cooperation on foreign and security policy. This is one example of a policy field where the subregional cooperation formats can provide a substitute or complement to the European Union and NATO.

The third chapter introduces the concept of identity and elaborates on the relevance of the concept for the study of subregional cooperation and integration. The role of the identity concept within the postfunctionalist theoretical perspective of the book is explained and situated in a context of the contemporary postfunctionalist and constructivist international relations literature. The book applies an understanding of identity as being about how a group manages to define itself in relation to other collectives by ascribing a stable meaning to itself. This understanding of identity suggests that stories, or narratives, are crucial for how a collective can obtain a feeling of being one unit with a common identity. It does not suggest that such a group identity 
would be exclusive. When it comes to subregions, their identities develop as complements to other identities at the national and regional levels. The identities are created through intentional and unintentional activities. In both subregions under scrutiny in the book there are frequent interactions between decision makers, civil servants and experts that suggest the possibility of elite socialization. Both subregions have also over time developed narratives about themselves. The chapter outlines the more specific narrative analysis deployed in the case studies based on the identification of the narratives' structure and identity, how the narratives relate change, how they provide ontological security and what norms they contain. The analysis also investigates how the narratives engage the broader publics of the subregions.

The fourth chapter provides the first case study examining the Nordic subregion. The chapter suggests that the great strength of Nordic subregionalism is the popular support it enjoys. During the Cold War the Nordic narrative was paradoxically a narrative that suggested that the Nordic region's main mission was about 'non-cooperation'. The high levels of trust between the Nordic countries was making this a low-tension area during the Cold War. The condition, however, was that the countries applied different alignment strategies in relation to the competing world powers and thus refrained from closer cooperation in sensitive areas. Since the end of the Cold War a new narrative has emerged; a narrative that emphasizes Nordic actorness and the cruciality of Nordic norms. These norms are coherent over time and the most crucial of them is a 'peace' norm. The Nordic Council has even suggested that peace should be the trademark of the region. The Nordic region survived an existential crisis in the 1990s when the relevance of the region was challenged but it has identified a new role for itself, and it can well be that the region manages to deliver on the ambition of the Nordic Council of Ministers that the region should be the most sustainable and integrated region in the world by 2030. If this happens it is the result of both Nordicization and Europeanization.

The fifth chapter of the book contains the second case study which is on the Visegrad Group. The group was established to provide stability in the region in the turbulent times shortly after the fall of the Iron Curtain. Quickly, however, its main mission became one of bringing the three (later four) countries of the region into European multilateral structures (in particular the EU and NATO). The successful transition became a part of the group's narrative in the years that followed successful EU and NATO accessions. The group presented itself as the good example to be followed for other transition countries and the group in line with this narrative pursued a policy of EU enlargement support and attempted to bring the countries of the Eastern Partnership closer to the EU. The post-accession story of the group is well in line with the group's earlier narrative of 'returning to Europe'. A narrative that primarily staged the countries as forerunners on EU accession and that also served to distance themselves 
from their communist past and Eastern Europe - the kidnapped West (Kundera 1984). During the last few years, in relation to the so-called migration crisis starting in 2015, a new story has established itself. This is partly linked to the difficulty of maintaining the relevance of the 'successful transition narrative' when the V4 countries are frequently criticized for failing on their commitment to democratic values. The new Visegrad narrative suggests that the V4 has a specific task to fulfil when it comes to protecting Europe and the process of European integration that is endangered among others as a consequence of previous EU decisions. The narrative serves to distinguish the V4 from other parts of the EU (primarily the Western) but it is by no means suggesting a departure of the countries from Europe.

In the sixth chapter the conclusions of the study are discussed. The conclusions stress that the examined subregions are different when it comes to their legitimacy claims: for the Visegrad Group the actual performance and what the group can deliver is more crucial, whereas the Nordic narrative is based on an understanding of shared norms that is stable over time. The concluding chapter of the book also contains a discussion on the future relationship between subregionalism and regionalism in Europe. It examines the role of the subregions in relation to the five different scenarios for future integration identified by the European Commission in its White Paper on the Future of Europe. The conclusion suggests that the subregions have the potential to play a bigger role in the integration process in case of the realization of the scenarios that suggest a partial reversal of the integration process, that is, the scenarios 'nothing but the single market' and 'doing less more efficiently'. The third scenario describing what the European integration process could look like by 2025 speaks of a more differentiated EU based on 'those who want more do more' and also in this context the subregions could play a more substantial role in compensating for horizontal differentiation, creating differences between the countries in a subregion, and in relation to vertical differentiation where the subregions can develop policies in fields where the European Union fails to do so. The subregions would be of less importance in case the fifth scenario of the Commission would materialize, that is in case the EU would enter the path of 'doing much more together'. The EU has, since the signing of the Rome Treaties in 1957, proved itself to be a surprisingly stable organization but relatively slow to change and reform. For that reason, perhaps the scenario of the Commission labelled 'carrying on' is the most likely one. In such case we can expect the subregions to continue their existence in the shadow of 'market power Europe', but with a gradual increase in importance because of the European integration process becoming more differentiated. 